\title{
A STUDY OF SALTY PROCESSED FOOD CONSUMPTION PATTERN AMONG DIFFERENT ETHNIC GROUP IN PATIENT WITH GASTRIC CANCER
}

\author{
Pun $R,{ }^{1}$ Katwal $B,{ }^{2}$ Mahaseth $R^{1}$
}

${ }^{1}$ Clinical Oncology Unit, Department of Medicine, ${ }^{2}$ Forensic Medicine, Nepal Medical College Teaching Hospital, Attarkhel, Gokarneshwor-8, Kathmandu, Nepal

\begin{abstract}
Gastric cancer is the fourth most frequently occurring malignancy, after lung, breast and colorectal cancer, and the second most common cause of death from cancer worldwide. The global incidence of gastric cancer shows wide geographic variation with a 15-20 fold difference between high and low incidence region. Therefore the prevention of gastric cancer represents one of the most important aspects of any cancer control strategy around the world. From the hospital based data in Nepal gastric cancer is the third most common cancer in males and the sixth common cancer in females. An observational hospital based descriptive study was carried out in the Oncology Unit of (NMCTH) from 2013-2018 on relationship between salty processed food consumption and increased possibility of development of gastric cancer in different ethnic groups of Nepal. Fifty-four diagnosed gastric cancer patients were enrolled and their dietary habits were extensively looked into. Of these $55.6 \%$ (30) were males and $44.4 \%$ (24) were females. The patient's age ranged between 25-75 years and the peak incidence was in age group 41-60 years. The habit of consumption of smoked meat was higher (77.8\%) than the consumption of packed food and fermented food. Tibeto-mongoloid ethnicity was found to have more prevalence $(64.8 \%)$ to gastric cancer. The common site of presentation of gastric cancer was at the antrum (44.4\%) and tubular adenocarcinoma was the most common type. It was the Tibeto-mongoloids whose food habit pattern comprised of major consumption of salty processed food and having more preference for salty processed food in daily life had increased high risk of gastric cancer than the other ethnic groups. This concludes that food consumption pattern play a critical role in the incidence of gastric cancer and dietary modification to reduce salt and salted food is a practical strategy with which gastric cancer risk can be prevented in these high risk ethnic group of Nepal.
\end{abstract}

\section{KEYWORDS}

Gastric cancer, ethnicity, dietary

habits, salty, processed, risk

\section{CORRESPONDING AUTHOR}

Dr. Rashmey Pun,

Consultant

Clinical Oncology Unit, Department of Medicine,

Nepal Medical College Teaching Hospital,

Attarkhel, Gokarneshwor-8, Kathmandu, Nepal

Email: dr.rpun@gmail.com

ORCID ID: https://orcid.org/0000-0002-1743-2147

DOI: https://doi.org/10.3126/nmcj.v22i3.32633 


\section{INTRODUCTION}

Gastric cancer is the fourth most frequently occurring malignancy, after lung, breast and colorectal cancer, and the second most common cause of death from cancer worldwide. ${ }^{1,2}$ It has been estimated that 1 million patients are newly diagnosed with gastric cancer worldwide each year, with 700,000 patients dying from this disease annually. ${ }^{1}$ The global incidence of gastric cancer shows wide geographic variation with a 15-20 fold difference between high and low incidence region. ${ }^{3}$ The highest gastric cancer incidence rate occurs in East Asia, South and Central America and Eastern Europe. ${ }^{4}$ Interestingly $74 \%$ of all global cases are from Asia. Therefore, the prevention of gastric cancer represents one of the most important aspects of any cancer control strategy around the world. The exact cancer prevalence rate in Nepal is unknown due to the lack of a population based national cancer registry. However, every year at least 26,000 new cancer cases are estimated and the figure is expected to go up considerably in the future. ${ }^{5}$ According to the present data from Nepal, it is the 5th commonest cancer including both genders, 3rd in males and 6th in females. ${ }^{6}$ Diet has been found to be an important factor in the development of gastric cancer..$^{7-10} \mathrm{~A}$ report published in 2007 by the World Cancer Research Fund and the American Institute for Cancer Research on the relationship between diet and cancer suggested that the consumption of certain types of food may be directly associated with the development of this disease. ${ }^{11}$

Several risk factors for stomach cancer have been known, including Helicobacter pylori $(\mathrm{H}$ pylori) infection, salt-preserved foods, dietary nitrite, smoking, alcohol, obesity, radiation, and family history. ${ }^{12,13}$ Researchers also studied that the incidence rates of stomach cancer varied across different geographic regions and this variation may be associated with genetic, lifestyle or environmental factors, including diet. ${ }^{14}$ Salt intake was first reported as a possible risk factor for stomach cancer in 1959. ${ }^{15}$ Based on the available experimental and epidemiologicaldata, a report from World Health Organization (WHO)/Food and Agriculture Organization (FAO) Expert Consultation in 2003 concluded that "salt-preserved foods and salt probably increase the risk of gastric cancer.”16 Dietary factors are important risk factors for determinants cancer in development. It is difficult to establish a causal relationship between salt intake and gastric cancer due to methodological limitations among which is the valid measurement of accurate salt intake. Therefore, the assumption is still unclear. In 2007, the Second Expert Report from the World Cancer Research Fund supported the view that salt intake is significantly related to gastric cancer. ${ }^{17}$ From then on, two meta-analyses have been published addressing the association between salt intake and gastrointestinal metaplasia or gastric cancer. The study on salt intake and gastrointestinal metaplasia revealed a positive trend but no statistical significance was observed..$^{18}$ It demonstrated a positive association between salt consumption and incidence rate of gastric cancer, the limitation in geographic location prevents its generalization. Therefore, we carried out this observational review to assess the association between food consumption pattern mainly processed salty food and gastric cancer and to find out the common histolopathological type of carcinoma.

\section{MATERIALS AND METHODS}

An observational hospital based descriptive study was done in Clinical Oncology Unit of Nepal Medical College Teaching Hospital (NMCTH) from 2013-2018. Ethical approval was obtained from the institutional review committee of Nepal Medical College. A total of 54 diagnosed gastric cancer patients who had histological confirmation besides the other parameters of supporting investigations were enrolled. Those with metastatic gastric cancer were also enrolled in the study. Helicobacter Pylori infection status was not mandatory and the age of the patients ranged from 25-75 years. Relevant clinical history of the patients were taken which included their clinical history, the signs and symptoms of the disease plus the dietary habits especially the consumption of salty processed food intake and the frequency of intake in different ethnic groups.

A processed food is a food item that has had a series of mechanical or chemical operations performed on it to change or preserve it. Processed foods are those that typically come in a box or bag and contain more than one item on the list of ingredients. In addition food processing is any method used to turn fresh food into food product. This can involve one or a combination of various processes including washing, chopping, pasteurizing, freezing, fermenting, packaging, cooking and many more. The food processing also include adding ingredients to food for example to extend shelf life. ${ }^{19}$ On the basis of the food consumed we tried to analyze the association between the salty processed food intake in different ethnicities and their particular dietary habit to be the possible risk factor for the development of gastric cancer.

Data was analyzed by using (Statistical Package for Social Sciences) SPSS version 17. Data was expressed as frequency, percentage and standard deviation. 


\section{RESULTS}

Fifty four gastric cancer patients over a period of 5 years from 2013-2018 were included in our study and of these $55.6 \%$ (30) were males and $44.4 \%$ (24) were females. The patients' age ranged between 25-75 years and the peak incidence was in age group 41-60 years (28/54 i.e. 52\%). The mean age of presentation of gastric cancer was 54.15 years with $+/-11.16$ years.

Out of 54 patients the frequency of different processed food consumption showed that smoked meat intake was higher with $77.8 \%$ than the consumption of packed food and fermented food like gundruk which were similar with $70.4 \%$ (Table 1) and the association of gastric cancer to smoking and alcohol consumption were $55.6 \%$ (Table 2, 3).

Tibeto-mongoloid had more prevalence to gastric cancer with $35 / 54$ patients (64.8\%). Dalit /others showed the least prevalence of the disease with 2/54 patients (3.7\%) while Indo-Aryans were 17/54 with $31.5 \%$ having gastric cancer (Table 4). The common site of presentation of gastric cancer was seen to be more at the antrum (44.4\%) followed by corpus (31.5\%) and fundus (18.5\%) and cardia was the least with $5.6 \%$ (Table 5).

Tubular adenocarcinoma was found to be the most common histopathological type accounting

Table 1: Different processed food patterns among the patients with gastric cancer

\begin{tabular}{|lcc|} 
Food pattern & $\mathbf{n}$ & $\mathbf{\%}$ \\
Smoked meat & 42 & 77.8 \\
Fermented food (Gundruk) & 38 & 70.4 \\
Packed Food & 38 & 70.4 \\
Total & $\mathbf{5 4}$ & $\mathbf{1 0 0}$ \\
\hline
\end{tabular}

Table 2: Association of gastric cancer and smoking

\begin{tabular}{|lcc|} 
Smoking & $\mathbf{n}$ & $\mathbf{\%}$ \\
Yes & 30 & 55.6 \\
No & 24 & 44.4 \\
Total & $\mathbf{5 4}$ & $\mathbf{1 0 0}$ \\
\hline
\end{tabular}

Table 3: Association of gastric cancer and alcohol consumption

\begin{tabular}{|lcc|} 
Alcohol & $\mathbf{n}$ & $\mathbf{\%}$ \\
Yes & 30 & 55.6 \\
No & 24 & 44.4 \\
Total & $\mathbf{5 4}$ & $\mathbf{1 0 0}$ \\
\hline
\end{tabular}

Table 4: Ethnicity of patients with gastric cancer

\begin{tabular}{|lcc|} 
Ethnicity & $\mathbf{n}$ & $\mathbf{\%}$ \\
Tibeto-mangoloids & 35 & 64.8 \\
Indo-Aryans & 17 & 31.5 \\
Dalits/Others & 2 & 3.7 \\
Total & $\mathbf{5 4}$ & $\mathbf{1 0 0}$ \\
\hline
\end{tabular}

Table 5: Different sites of gastric cancer

\begin{tabular}{|lcc|} 
Tumor site & $\mathbf{n}$ & $\mathbf{\%}$ \\
Antrum & 24 & 44.4 \\
Corpus & 17 & 31.5 \\
Fundus & 10 & 18.5 \\
Cardia & 3 & 5.6 \\
Total & $\mathbf{5 4}$ & $\mathbf{1 0 0}$ \\
\hline
\end{tabular}

\section{Table 6: Histopathological diagnosis}

\begin{tabular}{lcc} 
Histopathological diagnosis & $\mathbf{n}$ & $\mathbf{\%}$ \\
Tubular adenocarcinoma & 26 & 48.1 \\
Signet cell carcinoma & 9 & 16.7 \\
Mucinous adenocarcinoma & 3 & 5.6 \\
Undifferentiated carcinoma & 13 & \\
Neuroendocrine carcinoma & 2 & 3.7 \\
Sarcoma & 1 & 1.9 \\
Total & $\mathbf{5 4}$ & $\mathbf{1 0 0}$ \\
\hline
\end{tabular}

for $48.1 \%$ of carcinomas followed by signet ring cell type with $16.7 \%$ and mucinous and undifferentiated accounting for 5.6\% each. The least common histology seen was sarcoma (Table $6)$.

Gastric cancer of various histopathological types was more commonly seen in the age group 41-60 years (28/54) and was least were in age group less than 40 years with male preponderance. Likewise Tibeto-mongoloids were seen to be more affected by the disease $(35 / 54)$ followed by Indo-Aryans and Dalits/others 17 and 2 respectively (Table 7).

Tubular adenocarcinoma was the most common histopathological type in relation to different food consumption pattern which comprised of salty processed food like packed food, fermented food and smoked meat. However, the table above shows that the incidence of gastric cancer was seen to be more prevalent in the group that consumed smoked meat (Table 8).

Among the different ethnicity, it was the Tibetomongoloids whose food habit pattern comprised of extensive consumption of salty processed food like smoked meat, packed food and fermented food to be $85.7 \%, 74.3 \%$ and $68.6 \%$ respectively (Table 9). 
Table 7: Histopathological diagnosis in different age groups, sex and ethnicity

\begin{tabular}{|c|c|c|c|c|c|c|c|c|c|c|c|}
\hline : & $\%$ & 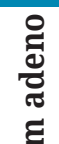 & $\%$ & ฮี & $\%$ & 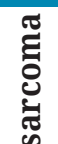 & $\%$ & & $\%$ & & $\%$ \\
\hline
\end{tabular}

\begin{tabular}{|lccccccccccccc|}
\hline Age group (years) & & & & & & & & & & & \\
$<=40$ & 1 & 1.85 & 0 & 0.00 & 0 & 0.00 & 0 & 0.00 & 2 & 3.70 & 3 & 5.56 & 6 \\
$41-60$ & 9 & 16.67 & 2 & 3.70 & 2 & 3.70 & 0 & 0.00 & 5 & 9.26 & 10 & 18.52 & 28 \\
$>60$ & 3 & 5.56 & 1 & 1.85 & 0 & 0.00 & 1 & 1.85 & 2 & 3.70 & 13 & 24.07 & 20 \\
Total & 13 & 24.07 & 3 & 5.56 & 2 & 3.70 & 1 & 1.85 & 9 & 16.67 & 26 & 48.15 & 54 \\
\hline Sex & & & & & & & & & & & & & \\
Male & 7 & 12.96 & 3 & 5.56 & 2 & 3.70 & 1 & 1.85 & 3 & 5.56 & 14 & 25.93 & 30 \\
Female & 6 & 11.11 & 0 & 0.00 & 0 & 0.00 & 0 & 0.00 & 6 & 11.11 & 12 & 22.22 & 24 \\
Total & 13 & 24.07 & 3 & 5.56 & 2 & 3.70 & 1 & 1.85 & 9 & 16.67 & 26 & 48.15 & 54 \\
\hline Ethnicity & & & & & & & & & & & & & \\
Dalits/others & 0 & 0.00 & 0 & 0.00 & 0 & 0.00 & 0 & 0.00 & 0 & 0.00 & 2 & 3.70 & 2 \\
Indo-aryans & 4 & 7.41 & 1 & 1.85 & 1 & 1.85 & 1 & 1.85 & 3 & 5.56 & 17 & 31.48 & 27 \\
Tibeto-mongol & 9 & 16.67 & 2 & 3.70 & 1 & 1.85 & 0 & 0.00 & 6 & 11.11 & 7 & 12.96 & 25 \\
Total & $\mathbf{1 3}$ & $\mathbf{2 4 . 0 7}$ & $\mathbf{3}$ & $\mathbf{5 . 5 6}$ & $\mathbf{2}$ & $\mathbf{3 . 7 0}$ & $\mathbf{1}$ & $\mathbf{1 . 8 5}$ & $\mathbf{9}$ & $\mathbf{1 6 . 6 7}$ & $\mathbf{2 6}$ & $\mathbf{4 8 . 1 5}$ & $\mathbf{5 4}$ \\
\hline
\end{tabular}

Table 8: food pattern and different histopathological types of gastric cancer.

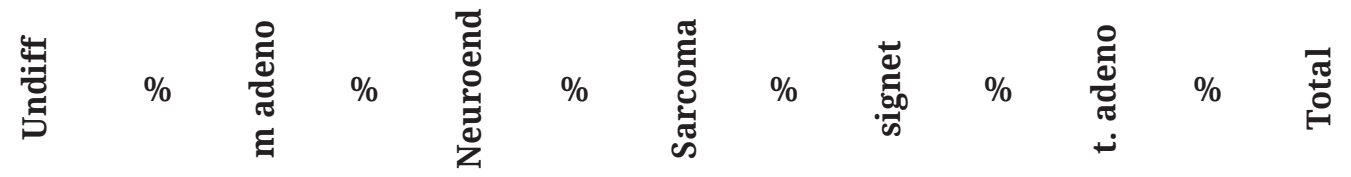

\begin{tabular}{|lccccccccccccc} 
Packed food & & & & & & & & & & & & & \\
Yes & 9 & 16.67 & 1 & 1.85 & 2 & 3.70 & 0 & 0.00 & 8 & 14.81 & 18 & 33.33 & 38 \\
No & 4 & 7.41 & 2 & 3.70 & 0 & 0.00 & 1 & 1.85 & 1 & 1.85 & 8 & 14.81 & 16 \\
Total & $\mathbf{1 3}$ & 24.07 & $\mathbf{3}$ & 5.56 & $\mathbf{2}$ & 3.70 & $\mathbf{1}$ & 1.85 & $\mathbf{9}$ & 16.67 & $\mathbf{2 6}$ & 48.15 & 54 \\
\hline
\end{tabular}

\begin{tabular}{lccccccccccccc} 
Fermented food & & & & & & & & & & & & & \\
Yes & 9 & 16.66 & 3 & 5.56 & 1 & 1.85 & 0 & 0.00 & 6 & 11.11 & 19 & 35.19 & 38 \\
No & 4 & 7.40 & 0 & 0.00 & 1 & 1.85 & 1 & 1.85 & 3 & 5.56 & 7 & 12.96 & 16 \\
Total & $\mathbf{1 3}$ & 24.07 & $\mathbf{3}$ & 5.56 & $\mathbf{2}$ & 3.70 & $\mathbf{1}$ & 1.85 & $\mathbf{9}$ & 16.67 & $\mathbf{2 6}$ & 48.15 & $\mathbf{5 4}$ \\
\hline
\end{tabular}

\begin{tabular}{|lccccccccccccc|}
\hline Smoked meat & & & & & & & & & & & & & \\
Yes & 11 & 20.4 & 3 & 5.56 & 1 & 1.85 & 0 & 0.00 & 8 & 14.81 & $\mathbf{1 9}$ & 35.19 & 42 \\
No & 2 & 3.70 & 0 & 0.00 & 1 & 1.85 & 1 & 1.85 & 1 & 1.85 & 7 & 12.96 & 12 \\
Total & $\mathbf{1 3}$ & $\mathbf{2 4 . 0 7}$ & $\mathbf{3}$ & $\mathbf{5 . 5 6}$ & $\mathbf{2}$ & $\mathbf{3 . 7 0}$ & $\mathbf{1}$ & $\mathbf{1 . 8 5}$ & $\mathbf{9}$ & $\mathbf{1 6 . 6 7}$ & $\mathbf{2 6}$ & $\mathbf{4 8 . 1 5}$ & $\mathbf{5 4}$ \\
\hline
\end{tabular}

\section{DISCUSSION}

The present study is based on hospital and a descriptive study. In our study, majority of the patients with gastric cancer were in the age range of 40 to 60 years which corroborates well with the study done by Gosh et al which shows the increase in incidence after 50 years. ${ }^{20}$ The study has demonstrated that the higher consumption of different types of salty packet food, fermented food like preserved pickles and gundruk (our local savory in Nepal) and salted smoked meat are found to incur high risk for gastric cancer. Gundruk is preserved spinach which is traditionally prepared by keeping it tightly packed moist vegetable in a jar for a few weeks or months, allowing fermentation.

Yang et al has mentioned similar pattern that salt processed vegetables including pickled and preserved vegetables were found to be commonly consumed in some areas with high risk of gastric cancer although some common fungi can reduce nitrate to nitrite, they also increase amines content of pickled vegetables. This can facilitate the endogenous formation of N-nitroso compounds, which have proven to be a strong carcinogenic to several sites of cancer. ${ }^{21}$ In addition to high 
Table 9: Food pattern among different ethnic groups.

\begin{tabular}{|c|c|c|c|c|c|c|c|}
\hline & $\begin{array}{l}\text { Dalits/ } \\
\text { Others }\end{array}$ & $\%$ & $\begin{array}{c}\text { Indo- } \\
\text { Aryans }\end{array}$ & $\%$ & $\begin{array}{c}\text { Tibeto- } \\
\text { mongoloids }\end{array}$ & $\%$ & Total \\
\hline \multicolumn{8}{|c|}{ Fermented food } \\
\hline Yes & 2 & 100 & 12 & 70.6 & 24 & 68.6 & 38 \\
\hline No & 0 & 0 & 5 & 29.4 & 11 & 31.4 & 16 \\
\hline Total & 2 & & 17 & & 35 & & 54 \\
\hline \multicolumn{8}{|c|}{ Smoked Meat } \\
\hline Yes & 0 & 0 & 12 & 70.6 & 30 & 85.7 & 42 \\
\hline No & 2 & 100 & 5 & 29.4 & 5 & 14.3 & 12 \\
\hline Total & 2 & & 17 & & 35 & & 54 \\
\hline \multicolumn{8}{|c|}{ Packed Food } \\
\hline Yes & 1 & 50.0 & 11 & 64.7 & 26 & 74.3 & 38 \\
\hline No & 1 & 50.0 & 6 & 35.3 & 9 & 25.7 & 16 \\
\hline Total & 2 & & 17 & & 35 & & 54 \\
\hline
\end{tabular}

salt in processed vegetables, it was reported that heavy contamination with fungi might exist as well during preservation, particularly during preparing preserved vegetables. ${ }^{4}$ Umesawa et $\mathrm{al}^{22}$ also showed the risk of gastric cancer was significantly higher among patients who preferred salty food compared to the ones who did not. Our study shows that, patients of different ethnicity in Nepal consuming different types of processed food on a daily basis show the increased risk of gastric cancer. Larsson et $\mathrm{al}^{23}$ also summarized that increased consumption of processed meat including salted meat was significantly associated with gastric cancer.

In our society depending on the ethnicity we have different traditional preparation, preservation and cooking processes which could be the probable risk factor of gastric cancer. In this study we came to know that Tibeto-mangoloids ethnic group show more risk to gastric cancer due to their food consumption habits where as IndoAryans and Dalit /others show less prevalence. An epidemiological study done by Ghosh et $\mathrm{al}^{20}$ shows $32 \%$ of Gurungs (Tibeto-mongoloids) were affected by gastric cancer than their other counterparts which supports our study which is $35.2 \%$.

It is possible that the increased risks in gastric cancer could be due to compounds other than salt in foods that were produced during the preservation process. ${ }^{24}$ In East Asia, salted foods and sauces are also high in nitrate, a chemical carcinogen, which may either be added to the foods or synergize from amino acids during fermentation. Nitrite and salt may work at an early stage in a synergistic fashion on stomach cancer carcinogenesis that might cause the strong associations between highly salted foods and gastric cancer. ${ }^{25,}{ }^{26}$ Salt intake, smoked meat, pickled vegetables, alcohol and tobacco are found to incur high risk and in our study smoked meat was found to be associated with increased risk of gastric cancer with $85.7 \%$, than the other counterparts like packed food (74.3\%) and fermented food like gundruk (68.6\%). Similarly alcohol consumption and smoking was found to be a higher risk factor than in non smokers and non- alcoholics. Our study is supported by the similar findings of Gosh et al where smoked meat was found to be associated with gastric carcinoma in Gurungs, Chhetris and Brahmins in $73 \%, 63 \%$, and $36 \%$ cases respectively. ${ }^{20}$

Our study shows that the commonest histological variety is the tubular adenocarcinoma with $48.1 \%$ having this variant. Bing et al describes that adenocarcinoma as the commonest histological variant and states that adenocarcinoma is often related to environmental factors such as Helicobacter pylori infection, diet and lifestyle while the diffuse type is more often associated with genetic abnormalities. ${ }^{26}$ The findings are closely similar to our study. Several mechanisms may account for the association between salty food intake and risk of gastric cancer. First, a high concentration of sodium in the stomach is reported to cause acute damage of the surface mucosal cells and transient cell proliferation. ${ }^{13}$ Second, a salty diet alters mucin production and enhances gastric chemical carcinogenesis. ${ }^{18}$

The result from our study also provides some evidence that salty processed food might contribute to high risk of gastric cancer. The most frequent site of stomach cancer is the distal stomach i.e., the antro-pyloric region. In our study, antrum was also seen to be the primary site with $44.4 \%$ followed by the body or corpus. Antrum was found to be the site of carcinoma in $70 \%$ (277 cases out of 397) of cases, thus being the most common site according to the study done by Gosh at el which is similar to our study. ${ }^{20}$ 
In conclusion this study demonstrated that some of the foods as packed food, salted smoked meat, fermented food etc. were extensively found in the dietary patterns of Tibeto-mongoloids than the other ethnic groups like Indo-Aryans and Dalits /others and it showed there was an increased risk of having gastric cancer in this particular ethnic group. This suggests that there is a positive dietary association related to the disease process and increased consumption of salty processed food was considered to be a risk factor. Reduction of salted processed foods intake in diet might be a practical and primary measure for preventing gastric cancer in this high risk population in Nepal.

\section{ACKNOWLEDGEMENT}

We would like to acknowledge Dr. Sujata Pudasaini, Associate Professor, Pathology Department, (NMCTH), Kathmandu, Nepal for guiding the author throughout the study.

\section{REFERENCES}

1. Parkin DM, Bray F, Ferlay J, Pisani P: Global cancer statistics, 2002. CA Cancer J Clin 2005; 55: 74-108.

2. Brenner H, Rothenbacher D, Arndt V: Epidemiology of stomach cancer. Methods Mol Biol 2009; 472: 467-77.

3. Sitarz R, Skierucha M, Meilko J et al. Gastric Ca: epidemiology prevention classification and treatment. Cancer Manag Res 2018; 10: 239-48.

4. Torre LA, Siegal RL, Ward EM, Jeimal A. Global Cancer Incidence and mortality rates and trends-an update. Cancer Epidemiol Biomarkers Prev 2016; 25: 16-27.

5. Ferlay J, Bray F, Pisani P, Parkin DM. GLOBOCAN 2002. Cancer Incidence, Mortality and Prevalence Worldwide. IARC Cancer Base No. 5 Version 2.0. Lyon, France: Pres Int'l Agen Res Cancer, 2004.

6. Ferlay J, Shin HR, Bray F, Forman D, Mathers C, Parkin DM. GLOBOCAN 2008, Cancer Incidence and Mortality Worldwide: IARC Cancer Base No. 10. Lyon, France: Intl Agen Res Cancer; 2010.

7. Nomura A: Stomach cancer. In Cancer epidemiology and prevention. Edited by: Schottenfeld D, Fraumeni. J New York, Oxford Univ Press; 1996:707-724.

8. Riboli E, Norat T: Cancer prevention and diet: opportunities in Europe. Pub Health Nutr 2001; 4: $475-84$

9. Key TJ, Schatzkin A, Willett WC, Allen NE, Spencer EA, Travis RC: Diet,nutrition and the prevention of cancer. Pub Health Nutr 2004; 7: 187-200.

10. Gonzalez CA: Nutrition and cancer: the current epidemiological evidence. Br J Nutr 2006; 96: 425 .

11. Wiseman M: The second World Cancer Research Fund/American Institute for Cancer Research expert report. Food, nutrition, physical activity, and the prevention of cancer: a global perspective. Proc Nutr Soc 2008; 67:253-56.

12. Crew KD, Neugut AI. Epidemiology of gastric cancer. World J Gastroenterol 2006; 12:354-62.

13. Forman D, Burley VJ. Gastric cancer: global pattern of the disease and an overview of environmental risk factors. Best Pract Res Clin Gastroenterol 2006; 20: 633-49.

14. Armstrong B, Doll R. Environmental factors and cancer incidence and mortality in different countries, with special reference to dietary practices. Int'l J Cancer 1975; 15: 617-31.

15. Sato T, Fukuyama T, Suzuki T, Takayanagi J. Studies of the causation of gastric cancer. The relationship between gastric mortality rate and salted food intake in several places in Japan. Bull Inst Public Health 1959; 8: 187-98.

16. World Cancer Research Fund, American Institute for Cancer Research Food, Nutrition and the Prevention of Cancer: a Global Perspective. Amer Inst Cancer Res 1997; 67.

17. World Cancer Research Fund, American Institute for Cancer Research: Food, Nutrition, Physical Activity, and the Prevention of Cancer: A global perspective. Amer Inst Cancer Res 2007.

18. Dias-Neto M, Pintalhao M, Ferreira M, Lunet N. Salt intake and risk of gastric intestinal metaplasia: systematic review and metaanalysis. Nutri Cancer 2010; 62: 133-47.

19. Wu Y, Fan Y, Jiang Y, Wang Y, Liu H, Wei M. Analysis of risk factors associated with precancerous lesion of gastric cancer in patients from Eastern China: A comparative study. J Can Res Ther 2013; 9: 205-9.

20. Ghosh A, Sathian B, Ghartimagar D, Narasimhan R, Talwar OP. Epidemiologic Analysis of Gastric Carcinoma in the Western Region of Nepal. Nep J Epidemiogyl 2010; 1: 27-32.

21. Yang C. Research on esophageal cancer in China: a review. Cancer Res 1980; 40:2633-44.

22. Umesawa M, Iso H, Fujino Y, Kikuchi S, Tamakoshi A; JACC Study Group. Salty Food Preference and Intake and Risk of Gastric Cancer : J Epidemiol 2016; 26: 92-7.

23. Larsson SC, Orsini N, Wolk A. Proccessed meat consumption and stomach cancer risk: a metaanalysis. J Nat'l cancer Inst 2006; 98: 1078-87.

24. Tsugane S, Tei Y, Takahashi T, Watanabe S, Sugano K. Salty food intake and risk of Helicobacter pylori infection. Jpn J Cancer Res 1994; 85: 474-7.

25. Ward MH, Lopez-Carrillo L. Dietary factors and the risk of gastric cancer in Mexico City. Am J Epidemiol 1999; 149: 925-32.

26. Bing $\mathrm{Hu}$, Nassim El Hajj, Scott Sittler, Nancy Lammert, Robert Barnes, Aurelia Meloni-Ehrig. Classification, histology and application of molecular pathology. J Gastrointest Oncol 2012; 3: 251-61. 